

\section{Sumário}

Crimes de responsabilidade do Presidente da República...............................................14 Carlos Ayres Britto

REFLEXÕES SOBRE O FUTURO DO ESTADO CONSTITUCIONAL MODERNO .22

Cesar Luiz Pasold, Gabriel Real Ferrer e Paulo Márcio Cruz

CONTRATOS PÚBLICOS Y MERCADO GLOBAL: UN ABORDAJE DESDE EL DERECHO ADMINISTRATIVO DEL SIGLO XXI.

Bruno Ariel Rezzoagli

CONTRATOS ADMINISTRATIVOS: CONCEITO E CRITÉRIOS DISTINTIVOS

Carlos Bastide Horbach

Os incentivos econômicos à compra de colhedoras pelo Pronaf-Mais alimentos para os PRODUtORES DE ARROZ IRRIGAdo do Rio GRANDE do Sul.

João Mairton Moura de Araújo, Mário Conill Gomes e André Carraro

LiMitAÇõES À EXTRAFISCALIDADE APLICÁVEIS AO FATOR ACIDENTÁRIO DE PREVENÇÃo - FAP...84 Daniel de Magalhães Pimenta

DesConstruindo A INEFICÁCIA DOS DIREITOS SOCIAIS: POR UMA RECONSTRUÇÃO DOS DIREITOS SOCIAIS DEMOCRÁTICA, PARTICIPATIVA E TRANSNACIONAL 106

Daniela Lopes de Faria, Christian Norimitsu Ito e Inês Moreira da Costa

DIREITO PROCESSUAL DE GRUPOS SOCIAIS ATUAL: ENTRE O ATIVISMO JUDICIAL E O GARANTISMO PROCESSUAL

Jefferson Carús Guedes

Políticas públicas, mínimo existencial e Poder Judiciário: a Questão do direito À moRADIA

Diogo de Calasans Melo Andrade 
BENEFíCIOS DE RENDA MÍNIMA COMO UM DIREITO FUNDAMENTAL: ACESSO À JUSTIÇA E INCLUSÃO

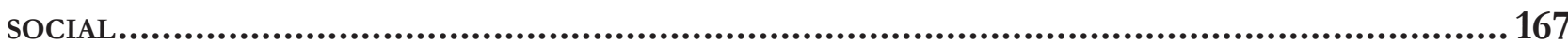

Pedro Bastos de Souza

DesenVolvimento humano SUSTENTÁVEl E ERRADiCAÇão dA POBREZA EXTREMA: UMA ANÁLISE

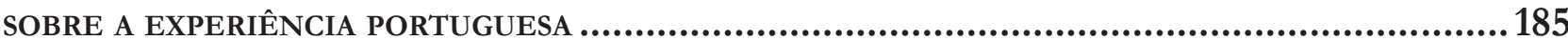

Veyzon Campos Muniz

A AÇÃO POPUlAR AMBIENTAL COMO FORMA DE PARTICIPAÇÃO SOCIAL NA DEFESA DO MEIO AMBIENTE ....203 Luciano Marcos Paes e Paulo Roberto Polesso

Direito PENAL AMBIENTAL COMO TUTEla de SUSTENTAÇÃo À ATUAÇÃo ADMINISTRATIVA E CIVIL nos Estados Unidos da AMÉrica E no Japão ...................................................214

Luiz Gustavo Gonçalves Ribeiro e Lorena Machado Rogedo Bastianetto

ConstruÇão Social do PRoJeto POlOS DE PRODUÇÃo DE BIODIESEL NO CONTEXTO do PNPB: UMA ANÁLISE PERCEPTIVA ......................................................................230

Érika Cristine Silva, Maria das Dores Saraiva de Loreto, Haudrey Germiniani Calvelli e Ronaldo Perez

A CORRElaÇão entre doenÇas respiratórias e o inCremento das Queimadas em Alta Floresta e Peixoto de Azevedo, norte do Mato Grosso - Amazônia Legal ....................246 Lilian Rose Lemos Rocha e Christopher William Fagg

Políticas públicas, agricultura familiar e Cidadania no Brasil: o caso do PRONAF ...... 256 Edir Vilmar Henig e Irenilda Ângela dos Santos

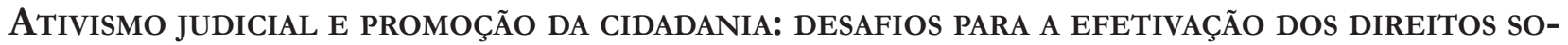
CIAIS CONSTITUCIONALIZADOS

Gerardo Clésio Maia Arruda, Adriana Rossas Bertolini e Jânio Pereira Cunha 


\title{
Contratos públicos y mercado global: un abordaje desde el derecho administrativo del siglo XXI*
}

\author{
Public contracts and global market: an \\ approach from the XXI century administrative \\ law
}

Bruno Ariel Rezzoagli**

\section{Resumen}

En el presente escrito se plantea la necesidad de propiciar un nuevo abordaje doctrinal de la contratación pública a partir de los principios emanados del incipiente orden jurídico administrativo global; el cual impacta, cada vez con mayor intensidad, en las regulaciones nacionales sobre la materia. El Derecho administrativo también ha sido alcanzado por la globalización, que rompe con los viejos esquemas de la contratación administrativa con un carácter estrictamente doméstico en pos de una innegable tendencia hacia la conformación un Derecho global de los contratos públicos.

Palabras claves: Contratos públicos. Globalización. Derecho administrativo. Potestades. Tradición continental.

\section{Abstract}

In this article there is a need to foster a new doctrinal approach to procurement from the principles enshrined in the emerging global administrative legal order; which strikes, with increasing intensity, national regulations on the subject. The administrative law also has been hit by globalization, which breaks the old schemes of government contracting with a purely domestic nature after an undeniable trend towards shaping a comprehensive law on public contracts.

Keywords: Procurement. Globalization. Administrative law. Powers. Continental tradition.

* Recebido em 21/01/2016 Aprovado em 05/06/2016

** Pós-doutorado em Finanças Públicas pelo Consejo Nacional de Investigaciones Científicas y Técnicas (Argentina). Doutor pela Universidade de Salamanca (Espanha). Professor da Universidad Nacional del Litoral. E-mail: brezzoagli@hotmail.com

\section{INTRODUCCIÓN}

Uno de los temas más importantes del Derecho administrativo es, sin lugar a dudas, la contratación pública. En efecto, en la actividad administrativa, junto con las manifestaciones de carácter unilateral se desarrollan acciones bilaterales en las que la Administración Pública entabla relaciones con otros 
sujetos; destacando, en el marco de este tipo de relaciones, la figura del contrato administrativo por su importancia jurídico-económica ${ }^{1}$.

Sin embargo, el tradicional entendimiento del Derecho administrativo se ve afectado por el surgimiento de un espacio jurídico-administrativo global, en el que habita toda una serie de regulaciones de tal carácter. Estamos, pues, frente a una realidad distinta que hay que analizar y comprender con una perspectiva diferente, con una mentalidad más abierta y plural porque, de lo contrario, quedaremos atrapados en aquellos prejuicios que atentan contra la evolución social ${ }^{2}$.

Es un gran error considerar que la enseñanza y aprendizaje del Derecho es un tema del pasado que poco importa frente a la tecnología moderna y las necesidades actuales; nada más importante que brindar la seguridad necesaria para crecer, que la presencia de la justicia y el Estado de Derecho, puesto que de ello depende el desarrollo de toda disciplina ${ }^{3}$.

Por ello, en la actualidad cuando nos referimos a la contratación pública, tenemos que hacerlo desde la perspectiva del Derecho administrativo del siglo XXI, que es fruto de participación, pluralismo y respeto a la dignidad humana ${ }^{4}$.

Cabe aclarar que los contratos del Estado se rigen por distintos regímenes jurídicos en los diferentes ordenamientos domésticos. Efectivamente, en unos países, por influencia del Derecho francés, se admite la figura del contrato administrativo, con la que se definen los contratos más frecuentemente celebrados por sus Administraciones (obras, suministros y servicios públicos) y cuya regulación se entiende objeto del Derecho administrativo sustantivo (sistema jurídico-administrativo continental); mientras que en la mayoría de los otros ordenamientos, los contratos que celebran las Administraciones públicas se consideran contratos privados sujetos a las normas comunes del Derecho civil y mercantil (sistema jurídico-administrativo de inspiración anglosajona) 5 .

En cualquier caso, tanto los unos como los otros tienen que ajustarse a este nuevo escenario que estamos comentando, que afecta más, como veremos a continuación, al sistema jurídico continental -de origen francés- (donde se ha desarrollado la teoría clásica de la noción de cláusula exorbitante que ba configurado la esencia del contrato administrativo) que al de inspiración anglosajona. Es por ello que en el presente artículo ahondaremos en el estudio de este emergente Derecho administrativo global -concretamente sobre el sector de la contratación pública-, de los denominados órganos administrativos globales, de los principios de este nuevo espacio jurídico, para luego reflexionar sobre su impacto en los ordenamientos domésticos sobre contratos públicos de los países con tradición jurídico-administrativa europeo continental.

\section{Globalización y Derecho administrativo}

El estudioso de la administración pública debe tener presente esta realidad en la que sectores de la actividad administrativa están sometidos a normas de carácter transnacional o intergubernamental, como es

1 NEVADO BATALLA, Pedro. Notas sobre derecho administrativo II. Salamanca: Ratio Legis, 2002. p. 123.

2 RODRÍGUEZ ARANA, Jaime et al. Derecho internacional de las contrataciones públicas. San José: Guayacán, 2011. p. 21.

3 GÓMEZ PALACIO, Ignacio. Enseñar, aprender y ejercer el Derecho ante los retos del cambio: evolución ineludible. En: ROJAS, Víctor Manuel (Coord.). La enseñanz̧a del Derecho en la Universidad Iberoamericana. México: Universidad Iberoamericana, 2002. p. 119. En este sentido el Profesor Rodríguez Arana señala que "ahora que percibimos la emergencia de este nuevo Derecho Administrativo en el que existe, todavía "in fieri”, una nueva Administración global que opera en el nuevo espacio jurídico global, es fundamental desde ya que los principios sobre los que va a descansar esta nueva realidad jurídico público se inscriban claramente en los postulados del Estado de Derecho”. Vid. RODRÍGUEZ ARANA, Jaime. El derecho administrativo global: un derecho principal. Administración de Andalucía: Revista Andaluza de Administración Pública, Sebilla, n. 76, ene./abr. 2010. p. 7.

4 PENAGOS, Gustavo. Nuevas tendencias del derecho administrativo a principios del siglo XXI. Revista Universitas, Bogotá, n. 106. p. 387, dic. 2003. p. 387.

5 MORENO MOLINA, José Antonio. El proceso de formación de un derecho global de la contratación pública. Revista DIXI, v. 14, n. 15 , p. 8-15, ene./jun. 2012. p. 12. 
el caso de la seguridad pública, la regulación de la energía, las telecomunicaciones, la inmigración, el medio ambiente, la llamada ayuda al desarrollo y muy especialmente, la contratación pública ${ }^{6}$.

Nuestros maestros nos enseñaban -me refiero principalmente a quienes nos formamos siguiendo una tradición juridica europeo continental- las notas distintivas de los contratos administrativos en torno al concepto de servicio público, cuya noción surgió en Francia caracterizada como actividad de determinado tipo realizada por la Administración en forma directa, o indirectamente a través de concesionarios, y fue el concepto que sirvió para la elaboración del viejo Derecho administrativo?

La relación con el servicio público era lo que justificaba la competencia de los tribunales llamados contencioso-administrativos, la naturaleza de contrato administrativo que asumían ciertos convenios con la Administración, el régimen jurídico del dominio público, la monopolización del servicio o falta de libre competencia, etc ${ }^{8}$. No obstante, la de "servicio público" es una noción que se revisa constantemente a fin de adecuar a ella las acciones que actualmente realiza la Administración pública; dado que la sociedad actual y, por consiguiente, sus necesidades, nada tienen que ver con el concepto de servicio público que vio la luz en el siglo XIX. Efectivamente, se trata de la institución jurídica más discutida y menos precisa en sus perfiles y en su determinación material y objetiva ${ }^{9}$.

En el ámbito contractual, la idea de lo público se vincula, por una parte, con el Estado como sujeto contratante pero, fundamentalmente, su principal conexión es con el interés general o bien común que persiguen, de manera relevante e inmediata, los órganos estatales al ejercer la función administrativa ${ }^{10}$.

En este sentido se expresa el Profesor de la Universidad de Salamanca Miguel Ángel González Iglesias al afirmar que "el contrato se nos presenta como uno de los instrumentos de la Administración para la consecución de sus fines", por lo tanto "es claro que la celebración de los mismos es parte integrante del elenco de potestades que las leyes le confieren a la misma para alcanzarlos. Potestad y contrato, por lo tanto, no son conceptos reñidos, sino que, por el contrario, el segundo se nos presenta como una aplicación de la primera"11.

Este fenómeno - el de la contratación pública- fue descripto, en la etapa de mayor auge de la tesis "ius administrativa" del contrato, como un sistema antagónico al de la contratación privada ${ }^{12}$. Las Administraciones públicas disfrutan de unas facultades exorbitantes en los contratos administrativos, tales como el poder de dirección, inspección y control de las obras, el poder de interpretación unilateral del contrato, la potestad de modificar el contrato por razón de interés público (potestas variandi), la potestad de suspender las obras por motivos de interés colectivo, la inaplicación general de las excepciones de incumplimiento administrativo, el régimen especial de mora administrativa, potestad de resolución unilateral del contrato y del principio de ejecutividad de los acuerdos ${ }^{13}$. Dichas prerrogativas traen su causa, desde otro plano, no del contrato, sino

6 RODRÍGUEZ ARANA, Jaime et al. Derecho internacional de las contrataciones públicas. San José: Guayacán, 2011. p. 20.

7 GORDILLO, Agustín. Tratado de derecho administrativo. 9. ed. Buenos Aires: Fundación de Derecho Administrativo, 2009 . p. VI-1.

8 GORDILLO, Agustín. Tratado de derecho administrativo. 9. ed. Buenos Aires: Fundación de Derecho Administrativo, 2009. . p. VI-1.

9 Vid. CHUAYFFET CHEMOR, Emilio. Derecho Administrativo. México: UNAM, 1983. (Introducción al Derecho mexicano, 4). p. 317; GARCÉS SANAGUSTÍN, Mario. La acción de fomento ante la nueva tipología de entes públicos. Presupuesto y Gasto Público, Madrid, n. 60, p. 7-23, 2010. p. 8; PONCE GÓMEZ, Francisco; PONCE CASTILLO, Rodolfo. Derecho fiscal. 11. ed. México: Limusa, 2007. p. 53; TRUCHET, Didier. Label de service public et statut du service public. Actualité Juridique-Droit Administratif, v. 1, 1982. p. 427-439.

10 CASSAGNE, Juan Carlos. El Derecho administrativo argentino: el derecho administrativo iberoamericano. Granada: INAP -UIM, 2005. p. 60 .

11 GONZÁLEZ IGLESIAS, Miguel Ángel. El contrato administrativo de consultoría y assistência. Madrid: Marcial Pons, 2002. p. 21.

12 CASSAGNE, Juan Carlos. Características principales del régimen de contrataciones de la Administración Nacional. Disponible en: < http:/ / www.cassagne.com.ar/publicaciones/Cassagne/CASSAGNE $\% 20-\% 20$ Caracteristicas $\% 20$ principales $\% 20 \mathrm{del} \% 20 \mathrm{RCAN}$.pdf>. Consultado el: 15 ago. 2012.

13 RODRÍGUEZ ARANA, Jaime. Las prerrogativas de la administración en los contratos de las administraciones Públicas. Anuario da Facultade de Dereito da Universidade da Coruña, n. 12, 2008. p. 801. Como ha señalado el profesor Ariño Ortiz "los "privilegios" 0 "prerrogativas de la Administración en la contratación son consecuencia obligada de dos factores: 1) la posición jurídica general de la Administración en el Estado moderno y 2) la tutela que el Derecho presta a los intereses públicos". Vid. ARIÑO ORTÍZ, Gaspar. La reforma de la ley de contratos del estado. Madris: Unión, 1984. p. 95. 
de la ley, no son expresión de un derecho subjetivo, sino de una potestad atribuida "ex lege" para atender los intereses públicos”"14.

Como se puede apreciar, la Administración pública históricamente ha sido concebida, en aquellos países con tradición administrativa de origen francés, como el poder a través del cual el Estado entra en contacto con los ciudadanos; siendo aquélla el centro de un Derecho administrativo autónomo, especial y exorbitan$\mathrm{te}^{15}$.

Sin embargo, la globalización no sólo ha propiciado la creación de órganos administrativos globales, que no realizan su actividad dentro de un Estado sino en el ámbito global (incluyendo los ordenamientos jurídicos supranacionales), también ha impuesto determinadas exigencias sobre las Administraciones domésticas, propendiendo a que su actuación sea racional, eficiente, transparente y con pleno sometimiento a la ley, como condiciones básicas para facilitar el libre tránsito de bienes y servicios ${ }^{16}$. En consecuencia, la mundialización del Derecho ha provocado un cambio de paradigma, donde la Administración es definida a partir del propio ciudadano y sus libertades, y no desde el poder o la prerrogativa ${ }^{17}$.

Hasta hace muy poco, a nadie se le ocurría dudar siquiera que el Derecho aplicable a la contratación administrativa era el ordenamiento jurídico doméstico y que, para el caso de que surgiera alguna disputa al respecto, la única jurisdicción competente sería la nacional, en concreto la contencioso-administrativa" ${ }^{18}$. No obstante, en una economía global donde predomina la inversión extranjera y el financiamiento multilateral para la ejecución de grandes obras, concesión de servicios públicos, etc., debemos reconocer junto al contrato administrativo regido por el derecho doméstico, la presencia de otras especies contractuales en las que se aplica preponderantemente el Derecho internacional y, en menor medida, el régimen jurídico administrativo doméstico (con la posibilidad de aplicación analógica del derecho privado) ${ }^{19}$.

Atendiendo a tal consideración, es común encontrarnos en las distintas legislaciones domésticas con la exclusión de determinados contratos (los contratos celebrados con Estados extranjeros, con entidades de derecho público internacional, con instituciones multilaterales de crédito, los que se financien, total o parcialmente, con recursos provenientes de esos organismos así como los comprendidos en operaciones de crédito público") del régimen general aplicable a la contratación administrativa ${ }^{20}$.

Como se puede apreciar, las Administraciones de los países con tradición administrativa inspiradas en el régimen francés también resultan alcanzadas por los controles propios del orden jurídico-administrativo global a través de principios que propenden a la racionalización de su actividad en beneficio de la gobernanza democrática, reduciendo el significativo ámbito de apreciación que deriva del sistema conceptual basado en

14 RODRÍGUEZ ARANA, Jaime. Las prerrogativas de la administración en los contratos de las administraciones Públicas. Anuario da Facultade de Dereito da Universidade da Coruña, n. 12, 2008. p. 803. Dicho autor aclara que tanto la operatividad del Estado social de Derecho como la esencia "vicarial” de la Administración, aconsejan (más allá de los presupuestos históricos que han configurado la esencia del Derecho Administrativo) el uso del término "potestad", en lugar de las expresiones "privilegios" o "prerrogativas".

15 HERNÁNDEZ G., José Ignacio. El concepto de administración pública desde la buena gobernanza y el derecho administrativo global: su impacto en los sistemas de derecho administrativo de la América española. Anuario da Facultade de Dereito da Universidade da Coruña, n. 16, p. 197-223, 2012. p. 201

16 HERNÁNDEZ G., José Ignacio. El concepto de administración pública desde la buena gobernanza y el derecho administrativo global: su impacto en los sistemas de derecho administrativo de la América española. Anuario da Facultade de Dereito da Universidade da Coruña, n. 16, p. 197-223, 2012. p. 201.

17 HERNÁNDEZ G., José Ignacio. El concepto de administración pública desde la buena gobernanza y el derecho administrativo global: su impacto en los sistemas de derecho administrativo de la América española. Anuario da Facultade de Dereito da Universidade da Coruña, n. 16, p. 197-223, 2012. p. 201.

18 CREMADES, Bernardo. La participación de los estados en el arbitraje internacional. Disponible en: < http://www.ohadac. com/labores-otras-contribuciones/items/la-participacion-de-los-estados-en-el-arbitraje-internacional.html>. Consultado el: 10 ago. 2012.

19 CASSAGNE, Juan Carlos. El Derecho administrativo argentino: el derecho administrativo iberoamericano. Granada: INAP -UIM, 2005. p. 60-61.

20 CASSAGNE, Juan Carlos. El Derecho administrativo argentino: el derecho administrativo iberoamericano. Granada: INAP -UIM, 2005. p. 61. 
la prerrogativa y el servicio público ${ }^{21}$. Principios que, en palabras de Rodríguez Arana, suponen una evidente limitación a una interpretación expansiva de lo que en materia de contratación pública se conoce como prerrogativas o privilegios de la Administración ${ }^{22}$.

Efectivamente, en el actual contexto económico mundial las famosas cláusulas exorbitantes, en cuanto prerrogativas de la Administración por razones de interés público, deben entenderse no como privilegios (ello obedece a una vieja concepción administrativa) sino como poderes cuyo ejercicio debe ser oportuno y respetar los parámetros de proporcionalidad y racionalidad ${ }^{23}$. Por lo tanto, no nos referimos a la supresión de las mismas, solamente a que su ejercicio esté de acuerdo con los citados principios; siendo éste, el principal reto del Derecho administrativo del siglo XXI.

\section{La tendencia hacia un Derecho administrativo global de la contratación pública}

En este nuevo escenario mundial comienzan a presentarse, para Meilán Gil, manifestaciones de la existencia de un Derecho administrativo global ${ }^{24}$, el cual resulta una consecuencia lógica del auge de sistemas transnacionales de regulación o cooperación regulatoria que se producen a través de tratados internacionales y redes intergubernamentales de cooperación más informales ${ }^{25}$. En tal sentido, muchos detalles de la implementación de dicha regulación corresponde a los denominados órganos globales que desarrollan funciones administrativas pero que no están sujetos directamente al control de los gobiernos nacionales o a los sistemas domésticos o, en el caso de los regímenes basados en tratados, a los Estados parte del mimo ${ }^{26}$.

Los órganos globales administrativos incluyen, conforme lo expresan los profesores Kingsbury, Krisch y Stewart ${ }^{27}$, organizaciones internacionales formales ${ }^{28}$, redes regulatorias informales intergubernamentales y arreglos de cooperación ${ }^{29}$, órganos regulatorios nacionales que operan en relación a un régimen internacional intergubernamental, órganos regulatorios híbridos público-privados ${ }^{30}$, y algunos órganos regulatorios privados que ejercen funciones de gobernanza transnacional de importancia pública específica ${ }^{31}$.

Respecto a la acción administrativa a nivel global, ésta incorpora la reglamentación administrativa ${ }^{32}$, el procedimiento administrativo que dirime intereses contrapuestos, y otras formas de decisiones y gestión regulatoria y administrativa. En definitiva, la acción administrativa global tiene, al igual que la doméstica, elementos tanto normativos como de carácter jurisdiccional ${ }^{33}$.

21 HERNÁNDEZ G., José Ignacio. El concepto de administración pública desde la buena gobernanza y el derecho administrativo global: su impacto en los sistemas de derecho administrativo de la América española. Anuario da Facultade de Dereito da Universidade da Coruña, n. 16, p. 197-223, 2012. p. 203.

22 RODRÍGUEZ ARANA, Jaime. Los principios del derecho global de la contratación pública. Derecho PUCP, n. 66, 2011 . p. 51.

23 RODRÍGUEZ ARANA, Jaime. Las prerrogativas de la administración en los contratos de las administraciones Públicas. Anuario da Facultade de Dereito da Universidade da Coruña, n. 12, 2008. p. 812.

24 MEILÁN GIL, José Luis. Una aproximación al derecho administrativo global. Sevilla: Derecho Global, 2011. p. 13.

25 RODRÍGUEZ ARANA, Jaime et al. Derecho internacional de las contrataciones públicas. San José: Guayacán, 2011. p. 26.

26 KINGSBURY, Benedict; KRISCH, Nico; STEWART, Richard. El surgimiento del Derecho Administrativo Global. Revista de Derecho Público, n. 24, Universidad de los Andes, mar. 2010. p. 6.

27 KINGSBURY, Benedict; KRISCH, Nico; STEWART, Richard. El surgimiento del Derecho Administrativo Global. Revista de Derecho Público, n. 24, Universidad de los Andes, mar. 2010. p. 7.

28 Basta con mencionar al Consejo de Seguridad de la ONU y comités derivados, el Alto Comisionado de las Naciones Unidas para los refugiados, la Organización Mundial de la salud, el Banco Mundial o Grupo de Acción Financiera Internacional.

29 Por ejemplo, el Comité de Supervisión Bancaria de Basilea.

30 Encuadran dentro de esta categoría: Comisión del Codex Alimentarius, Corporación de Internet para la Asignación de Nombres y Números (ICANN, por sus siglas en inglés).

31 Podemos citar, a modo de ejemplo, a la Organización Internacional de Normalización (ISO).

32 No en forma de tratados negociados por los Estados, pero sí de estándares y de reglas de aplicación general adoptadas por órganos subsidiarios. Efectivamente, ejercen funciones regulatorias de supervisión aquellos órganos cuasi-judiciales tales como el Órgano de Apelación del Órgano de Solución de Controversias de la OMC.

33 KINGSBURY, Benedict; KRISCH, Nico; STEWART, Richard. El surgimiento del Derecho Administrativo Global. Revista de 
Sin embargo, tal como expresa Rodríguez Arana, "ciertamente, esta cuestión es polémica, puesto que no toda la doctrina, ni muchos menos, admite que pueda haber regulación administrativa emanada más allá de órganos o estructuras no formalmente administrativas del nivel estatal o nacional, regional o subestatal' ${ }^{34}$.

Por otra parte, este proceso de formación del denominado Derecho administrativo global se ve reflejado con mayor nitidez en el terreno de los contratos públicos, puesto que éstos han sido objeto en las últimas décadas de importante legislación y acuerdos internacionales, como de jurisprudencia de órganos con jurisdicción internacional que han fijado principios generales, y de actuaciones administrativas, entre otras, de solución de controversias entre Estados u otras partes en disputa ${ }^{35}$.

Finalmente, Moreno Molina sostiene que el "Derecho administrativo global de los contratos públicos" es una noción que admite dos interpretaciones distintas, una restrictiva y otra en sentido amplio. En sentido estricto, este Derecho comprendería las normas y los principios que disciplinan la acción administrativa de las instituciones internacionales y de las administraciones nacionales como ejecutoras de esas decisiones; mientras que en un sentido más amplio, dicha noción describiría el proceso de desarrollo de un Derecho administrativo común en esta materia ${ }^{36}$.

\section{NoRMAS JURÍDICAS DE CARÁCTER INTERNACIONAL EN MATERIA DE CONTRATACIÓN PÚBLICA}

En el terreno internacional, debemos destacar los Acuerdos de contratación pública de la Organización Mundial de Comercio (OMC), las Normas de contratación pública del Tratado de Libre Comercio de América del Norte (TLCAN), el Protocolo sobre contrataciones públicas del Mercado Común del Sur (Mercosur), la llamada Ley modelo de contratación pública de Naciones Unidas (ONU), etc.

La mundialización de la economía, con la consecuente liberalización del comercio e innovación tecnológica, ha propiciado la celebración de acuerdos para estimular la inversión extranjera en los diferentes países; lo cual ha tenido una particular incidencia en materia de contratación pública dado que dichos acuerdos de inversión proporcionan el marco legal para que a su amparo se susciten los contratos con las entidades del sector público ${ }^{37}$.

Como se verá a continuación, los principales instrumentos jurídicos internacionales en materia de contratación se han construido sobre la base de los principios de no discriminación, de publicidad, de libre concurrencia, etc.; siendo expresión de la obligatoriedad que tienen las entidades gubernamentales y los entes del sector público, al gestionar fondos públicos, de actuar con transparencia y objetividad a los fines de adjudicar el contrato a la mejor oferta con miras al interés general ${ }^{38}$.

\subsection{El Acuerdo Plurilateral de Contratación Pública de la Organización Mundial de Comercio}

En el ámbito de las normas del comercio internacional, las contrataciones y adquisiciones públicas han sido históricamente omitidas ${ }^{39}$. En el Acuerdo General sobre Aranceles Aduaneros y Comercio (GATT)

Derecho Público, n. 24, Universidad de los Andes, mar. 2010. p. 7.

34 RODRÍGUEZ ARANA, Jaime. El derecho administrativo global: un derecho principal. Administración de Andalucía: Revista Andaluza de Administración Pública, Sebilla, n. 76, ene./abr. 2010. p. 22

35 MORENO MOLINA, José Antonio. La importante evolución hacia un Derecho Global de la Contratación Pública. En: PERNAS GARCÍA, J. José; MARTÍN RETORTILLO, María del Carmen Rodríguez (Coord.). La reforma de las Administraciones públicas. Madrid: Bubok, 2014. p. 499-516. p. 500.

36 MORENO MOLINA, José Antonio. El proceso de formación de un derecho global de la contratación pública. Revista DIXI, v. 14, n. 15 , p. 8-15, ene./jun. 2012. p. 10.

37 MEILÁN GIL, José Luis. Una aproximación al derecho administrativo global. Sevilla: Derecho Global, 2011. p. 60-61.

38 RODRÍGUEZ ARANA, Jaime. Los principios del derecho global de la contratación pública. Derecho PUCP, n. 66, 2011 . p. 31.

39 Vid. CONFERENCIA INTERNACIONAL DEL TRABAJO. Cláusulas de trabajo en los contratos celebrados por las autoridades 
de 1947, las compras públicas quedaron excluidas de forma explícita de la obligación fundamental de conceder trato nacional. Fue recién en 1979 cuando se firmó el primer Acuerdo sobre Compras del Sector Público, producto de las negociaciones comerciales de la Ronda de Tokio, que entró en vigencia en 1981 y se modificó en 1987 y cuya versión enmendada entró en vigor en 1988. Posteriormente, las Partes en el Acuerdo celebraron negociaciones para ampliar su alcance y aplicación, y cuyo resultado se ve reflejado en el Acuerdo sobre Contratación Pública que se firmó en Marrakech el 15 de abril de 1994, al mismo tiempo que el Acuerdo por el que se establece la OMC. El nuevo Acuerdo entró en vigor el $1^{\circ}$ de enero de $1996^{40}$.

Dicho acuerdo previó su propia revisión en los apartados b) y c) del párrafo 7 del artículo XXIV. El proceso para su reforma ha tenido dos momentos de gran relevancia, al llegarse a un primer acuerdo en el 2006 y culminar las negociaciones el 15 de diciembre del $2011^{41}$.

Se trata de un acuerdo plurilateral de compras públicas ${ }^{42}$ que supuso un hito fundamental en la liberalización en este sector, y que tiene por objetivo abrir a la competencia internacional la contratación de los gobiernos de sus paises signatarios, que se comprometen a aplicar procedimientos más transparentes y a asegurar un trato no discriminatorio a los bienes y servicios ofrecidos por empresas de cualquiera de ellos" ${ }^{33}$.

Además del principio de no discriminación ${ }^{44}$, el citado acuerdo establece procedimientos específicos a los que habrán de ajustarse los concursos públicos en relación a un amplio abanico de empresas públicas en los sectores del agua, la electricidad, los transportes urbanos, los puertos y aeropuertos ${ }^{45}$.

\subsection{Normas de contratación pública del Tratado de Libre Comercio de América del Norte}

El capítulo X del Tratado de Libre Comercio de América del Norte (en adelante, TLCAN), denominado "compras del sector público", tiene como objetivo principal la apertura de los mercados de adquisiciones y contrataciones públicas de Canadá, Estados Unidos y México a través de procedimientos de adjudicación claros, transparentes y predecibles, que garanticen un trato justo y no discriminatorio a todos los proveedores de la zona de libre comercio de América del Norte y, por ende, unas condiciones de igualdad en lo que respecta al acceso a la contratación pública de distintas áreas compradoras de los países suscriptores del citado tratado ${ }^{46}$.

Efectivamente, en dicho capítulo se establece que los países otorgarán a los bienes de otra parte, a los proveedores de dichos bienes y a los proveedores de servicios de otra parte, un trato no menos favorable que el más favorable otorgado a: a) sus propios bienes y proveedores, y b) los bienes y proveedores de otra parte. Además, el tratado prevé que ninguno de los miembros podrá: a) dar a un proveedor establecido localmente un trato menos

públicas. Genebra: OIT, 2008.

40 MORENO MOLINA, José Antonio. El proceso de formación de un derecho global de la contratación pública. Revista DIXI, v. 14, n. 15 , p. 8-15, ene./jun. 2012. p. 12; 13.

41 MORENO MOLINA, José Antonio. El proceso de formación de un derecho global de la contratación pública. Revista DIXI, v. 14 , n. 15 , p. 8-15, ene./jun. 2012. p. 16.

42 Es importante aclarar que los acuerdos de carácter plurilateral son aquéllos cuya aplicación únicamente recae sobre los miembros de la Organización Mundial de Comercio que hayan sido signatarios de los mismos; a diferencia de los que poseen carácter "multilateral", los cuales se aplican a todos los miembros de la citada Organización por el simple hecho de ser parte en el acuerdo por el que se crea la misma.

43 BONET BAIGET, Alfredo. Nuevas oportunidades en la contratación pública internacional. Boletín Económico de ICE, n. 3025 , abr. 2012. p. 1.

44 Conforme el párrafo 1, apartado a) del artículo III del acuerdo, las partes tienen que conceder a los productos, servicios y proveedores de las demás partes en el Acuerdo, un trato "no menos favorable" que el otorgado a sus productos, servicios y proveedores nacionales.

45 MONTAÑÁ I MORA, Miquel. Posibles modelos para la regulación de la competencia en la organización mundial del comercio. Revista Electrónica de Estudios Internacionales, n. 2, 2001. p. 5.

46 JIMÉNEZ VÁZQUEZ, Raúl. Consideraciones en torno al capítulo de compras del TLCAN y su eventual impacto en el Derecho mexicano. En: EL TRATADO de Libre Comercio de América del Norte: Análisis, diagnóstico y propuestas jurídicos, México: Instituto de Investigaciones Jurídicas; UNAM, 1993. p. 261. 
favorable que el otorgado a otro proveedor establecido localmente, en razón del grado de afiliación o de propiedad extranjeras; o b) discriminar contra un proveedor establecido localmente en razón de que los bienes o servicios ofrecidos por ese proveedor para una compra particular, sean bienes o servicios de otra parte ${ }^{47}$.

\subsection{El Protocolo de Contrataciones Públicas del Mercado Común del Sur}

En el ámbito del Mercado Común del Sur (fundado el 26 de marzo de 1991 como un espacio de integración intergubernamental mediante el tratado de Asunción suscrito por los representantes de Argentina, Brasil, Paraguay y Uruguay ${ }^{48}$ ) se adoptó, el 9 de diciembre de 2004, el Protocolo de contrataciones públicas del Mercosur mediante la Decisión del Consejo del Mercado Común No 27/04.

Los Estados Miembros del Mercosur adoptaron dicho protocolo con miras a extender gradualmente la transparencia en las contrataciones efectuadas por las entidades públicas ${ }^{49}$ y proporcionar a los proveedores y prestadores establecidos en los Estados partes y a los bienes, servicios y obras públicas originarios de esos Estados partes un tratamiento no discriminatorio en los procesos contractuales llevados a cabo por las entidades del sector público. En tal sentido, el art. 1 inc. 2 del citado protocolo, se establece que "Los procesos de contrataciones públicas de bienes, servicios y obras públicas deberán ser realizados de forma transparente, observando los principios básicos de legalidad, objetividad, imparcialidad, igualdad, debido proceso, publicidad, vinculación al instrumento de la convocatoria, concurrencia y los que concuerden con ellos".

En cuanto a su ámbito de aplicación, el art. $2^{\circ}$ dispone que "El Protocolo se aplica a las contrataciones públicas que las entidades de todos los niveles de gobierno federales y subfederales celebren para la adquisición de bienes y servicios, cualquiera sea su combinación, incluidas las obras públicas mediante cualquier método contractual', incluyendo en el Anexo I las entidades comprendidas en la norma.

En definitiva, este protocolo establece una mayor transparencia para las compras gubernamentales en base a la cláusula de la "Nación más favorecida" y el otorgamiento del "trato nacional" en buena parte de las licitaciones respectivas referidas a bienes, servicios y obra pública ${ }^{50}$. En efecto, ningún Estado parte podrá: a) discriminar a un proveedor o prestador establecido en cualquiera de los Estados Partes por motivo de uma afiliación o propiedad extranjera o, b) discriminar a um provedor o prestador estabelecido em su territorio em razón de que los bienes o servicios u obras públicas ofrecidos por ese proveedor o prestador, para una contratación en particular, sean de otro Estado Parte (art. 5 inc. 2).

\subsection{La Ley Modelo sobre Contratación Pública de Naciones Unidas}

La Comisión de Naciones Unidas para el Derecho Mercantil Internacional (CNUDMI) aprobó el 15 de junio de 1994 la denominada Ley Modelo sobre Contratación Pública, la cual se bien carece de valor normativo constituye una técnica indirecta para el desarrollo de relaciones económicas internacionales armonizadas entre los Estados, con diferentes sistemas jurídicos, sociales y económicos, en la medida que sus términos puedan considerarse favorablemente por sus Estados al promulgar o revisar las legislaciones sobre contratación pública ${ }^{51}$.

Esta ley modelo tiene como propósito central la promoción de la objetividad, la equidad y la participación en los procedimientos de adjudicación de los contratos públicos, así como la competencia empresarial y la transparencia, para alcanzar un uso óptimo de los recursos involucrados en la misma.

47 Vid. art. 1003 TLCAN.

48 GROS ESPIELL, Héctor et al. El derecho de la integración del Mercosur. Montevideo: U.M., 1999. p. 35 y ss.

49 Vid. CONFERENCIA INTERNACIONAL DEL TRABAJO. Cláusulas de trabajo en los contratos celebrados por las autoridades públicas. Genebra: OIT, 2008.

50 LUCÁNGELI, Jorge; SANGUINETTI, Mariana; ZAMORANO, Ana. Mercosur: la consolidación de la expansión de la economía del Bloque. Revista del CEI, n. 18, ago. 2010.

51 ESCRIHUELA MORALES, Francisco. La contratación del sector público: especial referencia a los contratos de suministro y de servicios. Madrid: La Ley, 2007. 
De conformidad con lo establecido en sus considerandos ${ }^{52}$, son objetivos de la misma los siguientes:

Alcanzar una máxima economía y eficiencia en la contratación pública;

Fomentar y alentar la participación de proveedores y contratistas en el proceso de contratación pública, sin hacer distinciones por concepto de nacionalidad, a fin de promover así el comercio internacional;

Promover la competencia entre proveedores o contratistas en orden al suministro del objeto del contrato adjudicable;

Garantizar un trato justo, igual y equitativo a todos los proveedores y contratistas;

Promover la rectitud y la equidad en el proceso de contratación, para que dicho proceso goce de la confianza pública; $y$

Dotar de transparencia a los procedimientos previstos para la contratación pública.

Sin lugar a dudas, se busca facilitar la armonización de la normativa internacional en una materia de gran importancia económica, y la de mayor interacción entre el sector público y los operados privados, como es la contratación pública. Efectivamente, nos referimos a las normas mencionadas anteriormente, y a otras, tales como por ejemplo las disposiciones de la Convención de las Naciones Unidas contra la Corrupción que trataremos a continuación.

\section{LA NORMATIVA COMUNITARIA EUROPEA SOBRE CONTRATOS PÚBLICOS}

Hemos decidido dedicar un apartado específico a la normativa comunitaria europea sobre contratación pública, dado que ésta constituye, en palabras del profesor Moreno Molina, "uno de los sectores en que el desarrollo del Derecho comunitario ha llegado más lejos y, consiguientemente, donde la armonización de los ordenamientos de los Estados miembros de la Comunidad se está produciendo con mayor intensidad"53.

La regulación de los contratos públicos es parte esencial de la política identificada por la Comisión y el Consejo de la Comunidad como necesaria para realizar el mercado interior ${ }^{54}$, el cual implica un espacio sin fronteras interiores, en el que esté garantizada la libre circulación de mercancías, personas, servicios y capitales $^{55}$.

Por lo tanto, el hacer efectivas las libertades fundamentales comunitarias necesarias para crear un mercado común (libertad de establecimiento, libre prestación de servicios, libre circulación de mercancías) constituye el fundamento legal de la acción comunitaria en el campo de la contratación pública; por lo que resulta inadmisible la existencia de reglamentaciones nacionales discriminatorias para empresas no nacionales, de normas que exigen la utilización de productos o bienes nacionales, el favorecimiento sistemático de las empresas nacionales, como de cualquier otra medida exclusionaria de la concurrencia intracomunitaria ${ }^{56}$.

Además, la política comunitaria europea para la apertura de los llamados mercados públicos ${ }^{57}$ a las reglas

52 Vid. Ley modelo sobre Contratación Pública.

53 MORENO MOLINA, José Antonio. El derecho de la Unión Europea en materia de contratación pública, organismo supervisor de las contrataciones del estado (OSCE). Lima, Perú. Disponible en: <http://www.osce.gob.pe/consucode/userfiles/image/moreno.pdf>.p. 11. 54 GIL ANTÓN, A. La aplicación del derecho comunitario y la repercusión en el ámbito territorial de la contratación pública de servicios financeiros. Noticias de la Unión Europea, v. 10, n. 119, p. 79-114, 1994. p. 71.

55 El Libro Blanco de la Comisión preveía, para la consecución de un mercado interior único, la desaparición de las fronteras físicas, técnicas y fiscales. Por lo que, este Libro contenía, dentro de su parte II que dedicaba a la supresión de las barreras técnicas, un apartado relativo a los contratos públicos, puesto que dicha eliminación se alcanzaría mediante la apertura del sistema interno de contratación pública a la concurrencia intracomunitaria.

56 JIMÉNEZ DE LAIGLESIA, José María. Adjudicaciones directas de contratos públicos y Derecho Comunitario. Comunidad Europea Aranzadi, Madrid, v.21, n. 7-8, p. 39-45, jul./ago. 1994. p. 39.

57 Vid. SAMANIEGO BORDIÚ, Gonzalo. La apertura de los contratos públicos en la Comunidad Europea: situación actual y 
efectivas de la competencia está basada en la idea de que esa apertura provoca significativos ahorros a las autoridades públicas intervinientes (reducción del gasto público), así como un beneficio sustancial al mercado en su conjunto ${ }^{58}$, en función a los estudios realizados a iniciativa de la Comisión sobre el Costo de la no Europa $^{59}$. En efecto, cuanto más numerosas sean las alternativas de elección mayores serán las posibilidades de beneficio entre las partes contratantes, ya que los oferentes se verán incentivados por la competencia a mejorar sus propuestas, y los demandantes podrán conocer y valorar un mayor número de ofertas en orden a seleccionar aquella que mejor satisfaga la ecuación precio-calidad ${ }^{60}$.

De cualquier manera, más allá de los beneficios que origina la apertura de mercado, como hemos señalado anteriormente, existe una tendencia a «comprar nacional», entendiendo por tal la decisión habitual de seleccionar casi siempre un proveedor nacional a pesar de que otro proveedor extranjero ofreciese mejores condiciones $^{61}$. Tendencia ésta que puede explicarse por el hecho de que los poderes públicos persiguen, a través de la contratación pública, no sólo comprar o realizar sus tareas más económicamente, sino también intervenir en la vida económica, social y política de su país ${ }^{62}$.

Por esta razón, la Unión Europea ha llevado a cabo un intenso programa legislativo tendiente a crear reglas que garanticen la apertura de ese sector comercial, reforzando la competencia y la transparencia, y suprimiendo todo obstáculo interpuesto por los operadores económicos ${ }^{63}$. Fruto de esta actividad normativa, han sido, entre otras, las directivas: 92/50/CEE, 93/36/CEE y 93/37/CEE, sobre coordinación de los procedimientos de adjudicación de los contratos públicos de servicios, de los contratos públicos de suministro y de los contratos públicos de obras, respectivamente; la Directiva 97/52/CE por las que se modifican las anteriores; las directivas 2004/17/CE y 2004/18/CE; así como las directivas 2014/23/UE, relativa a la adjudicación de contratos de concesión; 2014/24/UE, sobre contratación pública y por la que se deroga la directiva 2004/18/CE; y 2014/25/UE, relativa a la contratación por entidades que operan en los sectores del agua, la energía, los transportes y los servicios postales y por la que se deroga la directiva 2004/17/CE.

Estas directivas persiguen fundamentalmente la coordinación de los procedimientos de adjudicación de contratos públicos garantizando la publicidad adecuada de las ofertas, la libre concurrencia a los mismos y la supresión de toda medida discriminatoria ${ }^{64}$. Finalmente, uno de los objetivos principales de las nuevas directivas comunitarias del año 2014 es facilitar el acceso de las PYMEs a la contratación pública, mediante la reducción del "papeleo" para contratar, la incorporación de las nuevas tecnologías (contratación electrónica) a los fines de propiciar un fácil acceso a las licitaciones convocadas en cualquier lugar de Europa sin necesidad de contar con una gran estructura empresarial.

perspectivas. Noticias CEE, v. 8, n. 88, 1992. p. 103-106.

58 LOS CONTRATOS públicos en un Espacio Económico Único. Luxemburgo: Documentación europea, Oficina de Publicaciones Europeas, 1988. p. 11; GIL ANTÓN, A. La aplicación del derecho comunitario y la repercusión en el ámbito territorial de la contratación pública de servicios financeiros. Noticias de la Unión Europea, v. 10, n. 119, p. 79-114, 1994. p. 71.

59 El "Informe sobre el coste de la no Europa", realizado por la Comisión bajo la dirección de Paolo Cecchini, señalaba que debido a los sistemas proteccionistas de compras impuestos por los distintos Estados miembros, las autoridades públicas pagan más de lo que debieran en la adquisición de los bienes y servicios que necesitan, apoyando de esta forma a empresas subóptimas de la Comunidad (CECCHINI, P. Europa 1992: Una apuesta de futuro. Madrid: Alianza, 1988. p. 50 y ss).

60 OJEDA MARÍN, A. La Comunidad Europea y el GATT en el moderno sistema de contratación pública, RAP, n. 116, Madrid, 1988. p. 413.

61 SAMANIEGO BORDIÚ, Gonzalo. La normativa comunitaria de los contratos de las empresas que actúan en los sectores del agua, la energía, los transportes y las comunicaciones. REDA, n. 71, 1991. p. 358.

62 MATTERA, ALFONSO. EL Mercado Único Europeo: sus reglas, su funcionamento. Madrid: Civitas, 1991. p. 386.

63 SAMANIEGO BORDIÚ, Gonzalo. La apertura de los contratos públicos en la Comunidad Europea: situación actual y perspectivas. Noticias CEE, v. 8, n. 88, 1992. p. 103.

64 JIMÉNEZ DE LAIGLESIA, José María. Adjudicaciones directas de contratos públicos y Derecho Comunitario. Comunidad Europea Aranzadi, Madrid, v.21, n. 7-8, p. 39-45, jul./ago. 1994. p. 40. 


\section{A MODO DE REFLEXIÓN FINAL}

El recorrido realizado en estas páginas nos permite afirmar que estamos siendo verdaderos testigos del surgimiento y formación de un orden jurídico administrativo global, que provoca, particularmente en el ámbito de los contratos públicos, un significativo cambio de paradigma. Este replanteamiento de la contratación pública obedece al resquebrajamiento de la concepción exclusivamente doméstica de aquélla, dado que también comienza a ser alcanzada por los principios y controles propios de dicho Derecho global.

Efectivamente, este emergente orden jurídico global ha impactado y sigue impactando, incluso cada vez con mayor intensidad, en las regulaciones domésticas sobre contratación pública, propiciando que las organizaciones gubernamentales y demás entes del sector público respeten en su actuación contractual los principios de competencia, igualdad de trato, racionalidad, proporcionalidad, participación, transparencia y rendición de cuentas; los cuales modulan el ejercicio de los poderes o prerrogativas de la Administración en los países con tradición administrativa inspirada en el régimen francés.

\section{REFERENCIAS BIBLIOGRÁFICAS}

ARIÑO ORTÍZ, Gaspar. La reforma de la ley de contratos del estado. Madris: Unión, 1984.

BONET BAIGET, Alfredo. Nuevas oportunidades en la contratación pública internacional. Boletín Económico de ICE, n. 3025, abr. 2012.

CASSAGNE, Juan Carlos. Características principales del régimen de contrataciones de la administración nacional. Disponible en: <http://www.cassagne.com.ar/publicaciones/Cassagne/CASSAGNE\%20-\%20 Caracteristicas $\% 20$ principales $\% 20 \mathrm{del} \% 20 \mathrm{RCAN}$.pdf $>$.

CASSAGNE, Juan Carlos. El Derecho administrativo argentino: el derecho administrativo iberoamericano. Granada: INAP -UIM, 2005.

CECCHINI, P. Europa 1992: Una apuesta de futuro. Madrid: Alianza, 1988.

CHUAYFFET CHEMOR, Emilio. Derecho Administrativo. México: UNAM, 1983. (Introducción al Derecho mexicano, 4).

CREMADES, Bernardo. La participación de los estados en el arbitraje internacional. Disponible en: $<$ http://www.ohadac.com/labores-otras-contribuciones/items/la-participacion-de-los-estados-en-el-arbitraje-internacional.html>.

CONFERENCIA INTERNACIONAL DEL TRABAJO. Cláusulas de trabajo en los contratos celebrados por las autoridades públicas. Genebra: OIT, 2008.

ESCRIHUELA MORALES, Francisco. La contratación del sector público: especial referencia a los contratos de suministro y de servicios. Madrid: La Ley, 2007.

GARCÉS SANAGUSTÍN, Mario. La acción de fomento ante la nueva tipología de entes públicos. Presupuesto y Gasto Público, Madrid, n. 60, p. 7-23, 2010.

GIL ANTÓN, A. La aplicación del derecho comunitario y la repercusión en el ámbito territorial de la contratación pública de servicios financeiros. Noticias de la Unión Europea, v. 10, n. 119, p. 79-114, 1994.

GÓMEZ PALACIO, Ignacio. Enseñar, aprender y ejercer el Derecho ante los retos del cambio: evolución ineludible. En: ROJAS, Víctor Manuel (Coord.). La enseñanza del Derecho en la Universidad Iberoamericana. México: Universidad Iberoamericana, 2002. 
GONZÁLEZ IGLESIAS, Miguel Ángel. El contrato administrativo de consultoría y assistência. Madrid: Marcial Pons, 2002.

GONZÁLEZ-VARAS IBÁÑEZ, Santiago. El contrato administrativo. Madrid: Civitas, 2003.

GONZÁLEZ-VARAS IBÁÑEZ, Santiago. El control sobre la adjudicación mediante concurso y el Derecho Comunitario europeo: Sentencias del Tribunal de Justicia de las Comunidades Europeas de 17 de septiembre de 2002 (Asunto c-513/99) y de 18 de junio de 2002 (Asunto c-92/00). Noticias de la Unión Europea, n. 219, p. 21-25, 2003.

GONZÁLEZ-VARAS IBÁÑEZ, Santiago. La Administración y las nuevas tecnologías. Asamblea: Revista Parlamentaria de la Asamblea de Madrid, n. 7, p. 215-240, 2002.

GORDILLO, Agustín. Tratado de derecho administrativo. 9. ed. Buenos Aires: Fundación de Derecho Administrativo, 2009.

GROS ESPIELL, Héctor et al. El derecho de la integración del Mercosur. Montevideo: U.M., 1999.

HERNÁNDEZ G., José Ignacio. El concepto de administración pública desde la buena gobernanza y el derecho administrativo global: su impacto en los sistemas de derecho administrativo de la América española. Anuario da Facultade de Dereito da Universidade da Coruña, n. 16, p. 197-223, 2012.

JIMÉNEZ DE LAIGLESIA, José María. Adjudicaciones directas de contratos públicos y Derecho Comunitario. Comunidad Europea Aranz̧adi, Madrid, v.21, n. 7-8, p. 39-45, jul./ago. 1994.

JIMÉNEZ VÁZQUEZ, Raúl. Consideraciones en torno al capítulo de compras del TLCAN y su eventual impacto en el Derecho mexicano. En: EL TRATADO de Libre Comercio de América del Norte: Análisis, diagnóstico y propuestas jurídicos, México: Instituto de Investigaciones Jurídicas; UNAM, 1993.

KINGSBURY, Benedict; KRISCH, Nico; STEWART, Richard. El surgimiento del derecho administrativo global. Revista de Derecho Público, n. 24, mar. 2010.

LOS CONTRATOS públicos en un Espacio Económico Único. Luxemburgo: Documentación europea, Oficina de Publicaciones Europeas, 1988.

LÓPEZ-FONT MÁRQUEZ, José Francisco. La apertura de los procedimientos nacionales de adjudicación de los contratos públicos a las empresas de otros Estados miembros de la Unión Europea. RAP, Madrid, n. 133, 1994.

LUCÁNGELI, Jorge; SANGUINETTTI, Mariana; ZAMORANO, Ana. Mercosur: la consolidación de la expansión de la economía del Bloque. Revista del CEI, n. 18, ago. 2010.

MATTERA, ALFONSO. EL Mercado Único Europeo: sus reglas, su funcionamento. Madrid: Civitas, 1991.

MEILÁN GIL, José Luis. Una aproximación al derecho administrativo global. Sevilla: Derecho Global, 2011.

MONEDERO GIL, José Ignacio. Doctrina del contrato del estado. Madrid: IEF, 1977.

MONTAÑÁ I MORA, Miquel. Posibles modelos para la regulación de la competencia en la organización mundial del comercio. Revista Electrónica de Estudios Internacionales, n. 2, 2001.

MORENO MOLINA, José Antonio. El derecho de la Unión Europea en materia de contratación pública, organismo supervisor de las contrataciones del estado (OSCE). Lima, Perú. Disponible en: < http://www.osce.gob.pe/consucode/userfiles/image/moreno.pdf>.

MORENO MOLINA, José Antonio. El nuevo derecho de la contratación pública: de las prerrogativas de la administración a la garantía de los principios generales. Madrid: INAP, 2010. (La Administración Pública entre dos siglos). 
MORENO MOLINA, José Antonio. El proceso de formación de un derecho global de la contratación pública. Revista DIXI, v. 14, n. 15, p. 8-15, ene./jun. 2012.

MORENO MOLINA, José Antonio. La importante evolución hacia un Derecho Global de la Contratación Pública. En: PERNAS GARCÍA, J. José; MARTÍN RETORTILLO, María del Carmen Rodríguez (Coord.). La reforma de las Administraciones públicas. Madrid: Bubok, 2014. p. 499-516.

NEVADO BATALLA, Pedro. Notas sobre derecho administrativo II. Salamanca: Ratio Legis, 2002.

NOGUERA DE LA MUELA, Belén. Las directivas comunitarias de los sectores excluidos y la ley 48/98, de 30 de diciembre: ámbito de aplicación y procedimientos de conciliación. Noticias de la Unión Europea, n. 205, 2002.

OJEDA MARÍN, A. La Comunidad Europea y el GATTT en el moderno sistema de contratación pública, RAP, n. 116, Madrid, 1988.

PENAGOS, Gustavo. Nuevas tendencias del derecho administrativo a principios del siglo XXI. Revista Universitas, Bogotá, n. 106, p. 387, dic. 2003.

PONCE GÓMEZ, Francisco; PONCE CASTILLO, Rodolfo. Derecho fiscal. 11. ed. México: Limusa, 2007. RODRÍGUEZ ARANA, Jaime. El derecho administrativo global: un derecho principal. Administración de Andalucía: Revista Andaluza de Administración Pública, Sebilla, n. 76, ene./abr. 2010.

RODRÍGUEZ ARANA, Jaime et al. Derecho internacional de las contrataciones públicas. San José: Guayacán, 2011.

RODRÍGUEZ ARANA, Jaime. Las prerrogativas de la administración en los contratos de las administraciones Públicas. Anuario da Facultade de Dereito da Universidade da Coruña, n. 12, 2008.

RODRÍGUEZ ARANA, Jaime. Los principios del derecho global de la contratación pública. Derecho PUCP, n. 66, 2011.

SAMANIEGO BORDIÚ, Gonzalo. La apertura de los contratos públicos en la Comunidad Europea: situación actual y perspectivas. Noticias CEE, v. 8, n. 88, 1992.

SAMANIEGO BORDIÚ, Gonzalo. La normativa comunitaria de los contratos de las empresas que actúan en los sectores del agua, la energía, los transportes y las comunicaciones. REDA, n. 71, 1991.

SANTAMARÍA PASTOR, José Antonio. Principios de derecho administrativo. Madrid: Centro de Estudios Ramón Areces, 1990. v. 2.

TRUCHET, Didier. Label de service public et statut du service public. Actualité Juridique-Droit Administratif, v. 1,1982 . 
Para publicar na revista Brasileira de Políticas Públicas, acesse o endereço eletrônico www.rbpp.uniceub.br

Observe as normas de publicação, para facilitar e agilizar o trabalho de edição. 